\title{
Eleştiri Kültürünün Konya Türkülerine İz Düşümü*
}

\author{
Doç. Dr. Sinan Gönen \\ Selçuk Üniversitesi Edebiyat Fakültesi \\ Türk Dili ve Edebiyatı Bölümü \\ sgonen@selcuk.edu.tr
}

Öz

Halk şiirinin önemli türlerinin başında türküler gelmektedir. Yüzyıllardan bu tarafa Türk sözlü kültürünün zenginlikleri içerisinde yer alan türküler, insanımızın aşklarını, sevgilerini, sevinçlerini, kederlerini, vb. yansıtmıştır. Türküler, kendine has farklı ezgileriyle çeşitlilik arz ederken, işlediği konu ve şekil açılarından da farklılıklar gösterirler. Ayrıca, türküler anonim olabildiği gibi, ferdi olan türküler de bulunmaktadır. Türkülerde, günlük yaşamın içinde insanın karşılaşabileceği bütün durumlar konu olarak işlenmiştir. Elbette, günlük yaşama dair bakış açılarının içinde, eleştirel yaklaşımlar da türkülerde kendine yer bulabilmiştir. Türküler içerisinde, Konya türkülerinin kendine özgü farklı bir yeri vardır. Bu makalede, Konya türkülerinde yer alan eleştiri kültürü ayrıntılı olarak ele alınmış ve eleştirinin sebepleri, çeşitleri, sınırları, vb. hususlarda türkülerin işlevi ortaya konulmaya çalışılmıştır. Burada Konya türküleri özelinde, eleştirel bakış açısının kümelendiği belli başlı hususlar örnekleri ile ortaya konulmuştur. Özellikle örneklerde görüleceği gibi, evliliğin çeşitli yönleriyle ilgili eleştirilerin yoğunlaştığı görülmüş; ayrıca sevgili, kaynana, komşu, yakınlar, düşman, vb. insanın çevresinde var olan, hayatta karşılaşabileceği kişiler de eleştirilmiştir. Bunun yanında hastalık, ölüm, hayatın getirdiği beklenilmeyen durumlar da türkülerde eleştirilen konular içerisinde bulunmaktadır.

Anahtar Kelimeler: Konya, türkü, işlev, eleştiri.

\section{Culture of Criticism's Reflection on Konya's Folk Songs}

\begin{abstract}
Folk songs are one of the main important types of folk poetry. Folk songs, contained within richness of Turkish oral culture for centuries, have reflected our people's love, liking, happiness, sadness etc. Folk songs both indicate variety with idiocratial melodies and show distinctness in terms of theme and form. Also, folk songs can be both anonymous and personal. In folk songs, all circumstances that the human can experience in the daily life have been treated as theme. Of course, there are critical approaches that are viewpoints about daily life in folk songs. In folk songs, Konya's folk songs have idiocratial and different position. In this paper, culture of criticism have been analyzed in Konya's folk songs broadly and function of folk songs have been attempted to be revealed on causes, types, verges etc.
\end{abstract}

${ }^{*}$ Bu makale, Uluslararası Türkçe Kongresi (Saraybosna-Bosna Hersek 23-27 Mayıs 2016)'nde bildiri olarak sunulmuş, basılı olmayan metnin genişletilmiş hâlidir. 
of folk songs. At this point, specific to Konya's folk songs, main subjects that include critical point of view have been revealed with examples. Especially, it has been seen that criticisms are in majority about several aspects of marriage. Also, people around the human have been cricitised such as the darling, mother-in-law, neighbour, intimates, enemy etc. as it can be seen in the examples. In addition, illness, death, unexpected situations have been cricitised in folk songs.

Keywords: Konya, folk song, function, criticism. 


\section{GíRIŞ}

Türküler, halk şiiri içerisinde kendine has bir yer edinmiştir. Söyleyicileri belli olmayan, anonim olan türküler olduğu gibi ferdi türküler de bulunmaktadır. Halk şiiri türlerinden ninni, mani ağıt gibi türleri de içerisinde kolayca barındırabilen türkü türü yüzyıllar boyunca toplumun aynası olmuştur. Duygu ve düşüncelerin karşıya ifade ediliş formu olarak her dönemde sözlü kültür içerisinde yaşamış olan türküler, günümüzde de duyguları gönüllerden gönüllere geçiren vasıta konumundadır.

"Türküler iki kaynaktan beslenir: Asıl türküler, yakıcıları (söyleyenleri) bilinmeyen, anonim nitelikte olanlardır. Şüphesiz, bunların bir ilk söyleyeni vardır; ama ya adını koymamıştır, ya da zamanla bu ada unutulmuş ve türkü topluma mal olmuştur. Türkü'yü öbür türlerden ayıran en önemli ayrımlardan biri de budur. Kimi zaman bir sazşairinin söylediği bir parça, sonradan türkü haline gelir. Parça da adı geçsin geçmesin, o şiir, halkça türkü olarak bilinir. Özel bir ezgi eşliğinde söylenir." (Dizdaroğlu 1969: 104)

Şekil olarak bentler ve bağlamalardan oluşan türküler, genellikle üçe ayrılarak incelenmiştir: "I. Ezgilerine göre türküler (usulsüz/uzun havalar, usullü/oyun havaları), II. Konularına göre türküler (lirik, satirik, olay, tören ve mevsim, iş ve meslek, pastoral, didaktik ve oyun türküleri) ve III. Yapılarına göre türküler (yapılarında belli bir düzen bulunmayanlar, yapılarında belli bir düzen bulunanlar/bentler ve bağlamalar)." (Yardımcı 2008: 109-130).

Türkülerde konu açısından insanı ilgilendiren hemen bütün yönler işlenirken, farklı ezgi ve yapılarla metinler karşımıza çıkmaktadır.

Bazen türküler yörelere göre farklılık arz ederken, bazen de söyleyicileriyle de bütünleşmiştir. Örneğin Karacaoğlan'ın koşmalarının bir kısmı türküleşirken, yakın dönemde kaybettiğimiz Neşet Ertaş'ın ismi de türküleriyle bütünleşmiştir.

Türkülerle ilgili eserinde Ali Yakıcı türkülerle ilgili birçok tanımı verdikten sonra şu tespiti yapar: "Her ne kadar, türkü tanımıyla ilgili alıntı yaptığımız kimi sözlük, kitap ve ansiklopedilerde halk şiiri nazım şekli olarak verilmişse de, genel kabule ve eldeki verilere göre türkü, nazım şekli olarak düşünülmemelidir. Çünkü mani, koşma, gazel vb. nazım şekillerinden oluşturulmuş kimi şiirler türkü olarak repertuvardaki yerini alabilmektedir. Bu nedenle türkünün nazım şekli değil, bir tür olarak düşünülmesi gerekir." (Yakıcı 2007: 48)

İnsanı ilgilendiren hemen her konunun türkülerde konu edindiğini söylemiştik. Burada türkülerde eleştiri kültürünün varlığı Konya özelinde ele alınmıştır.

Elbette eleştiri kavramı akıllara öncelikle olumsuz yönüyle gelmektedir. Kavramın konumuzla ilgili anlam dairesine bakacak olursak;

"Bir insanı, bir eseri, bir konuyu doğru ve yanlış yanlarını bulup göstermek amacıyla inceleme işi, tenkit; Bir edebiyat veya sanat eserini her yönüyle değerlendirerek anlaşılmasını sağlamak amacıyla yazılan yazı türü, tenkit, kritik; Özellikle bilginin temellerini ve doğruluk durumunu inceleme, sinama, yargilama." (www.tdk.gov.tr) Burada da görüleceği üzere eleştiri kavramı, olumsuz yönlerin yanında olumluyu da önceleyen tarafları ortaya koymayı amaçlamaktadır.

Genel olarak halk biliminin, özelde ise burada türkülerin işlevleri arasında yer alan eleştiri konusuna geçmeden önce folklorun işlevlerini W. R. Bascom şöyle açıklamaktadır: “1. Eğlenme, Eğlendirme ve Hoşça Vakit Geçirme İşlevi, 2. Toplumsal Kurumlara ve Törenlere Destek Verme İşlevi, 3. Eğitim ve Kültürün Genç Kuşaklara Aktarılması İşlevi, 4. Toplumsal ve Kişisel Baskılardan Kurtulma İşlevi" (Bascom 2005: 137-142, Ekici 2007: 124-

SEFAD, 2017 (38): 419-432 
126'dan). Buradaki özellikle son madde türkülerde yer alan eleştirel bakış açısına uygun düşmektedir. Aşağıdaki başlıklarda da bu durum açıkça gözlemlenebilir.

Eleştiri kavramının türküler bağlamında varlığına burada Konya türküleri üzerinde kısaca değinilecektir. Konya, türkü geleneğinin toplu eğlencelerin başında gelen dügüülerin yanında özellikle barana geleneği/Konya oturak geleneği etrafında yaşatılan ve türkü icracılarının katkılarıyla yaşattığı bir coğrafyadır.

“...oturak; Konya'da şehir muhiti musiki meclislerine verilen bir isimdir. Konya'da oturak denildiği zaman, hemen akla ilk gelen; şehir muhiti musiki meclisleridir. Buna göre, denilebilir ki oturak kelimesi, Konya'da; kültürel yaşantının bütün unsurlarını içermekle beraber, esas olarak halk müziği ve oyunları ile eş anlamlı değerlendirilir." (Sakman 2001: 7)

"Genellikle gençler ve yetişkinler arasında sosyal dayanışmayı sağlayan ve temelde sohbet ve eğlenceye dayalı bir geleneksel kültür unsuru olan barana, Türkiye'nin farklı bölgelerinde, ad olarak aynı olmakla birlikte, icra töreleri, sosyokültürel ortamı ve icra mekânları bakımından farklılık göstermektedir. Günümüzde, Türkiye'nin özellikle iki ayrı bölgesinde 'geleneksel barana kültürü' yaşamakta ve yaşatılmaktadır." (Yakıcı 2010: 95)

"Konya barana kültüründe de sohbetin yanı sıra müzik icrası ön plânda ve daha belirgindir. Burada, müzik dışındaki yüzük oyunu vb. aktivitelere pek yer verilmediği, toplum baskısından uzakta, daha özgür mekân ve ortamlarda bir müzik icrası gerçekleştirildiği görülmektedir. Konya baranasında, mahalli söyleyişle 'kadın oynatma' ya da müzik diliyle 'oturak âlemi' olarak bilinen ve diğer sohbet toplantılarında pek görülmeyen bir eğlence icrası varlığını sürdürmektedir." (Yakıcı 2010: 96)

"Konya türkülerinin her biri önemli bir olayı ölümsüzleştirir. Pek çok türkümüzün hikayesi dillerdedir. Konya'nın önemli bir âşık merkezi olması nedeniyle, türkülerimizin mısra yapısı çok sağlamdır. Ancak türkü güftelerinin oturaklarının yozlaşması sürecinde, oturak ortamına uyarak mısra yapıları bozulmuştur. Özellikle türkülerinin nakaratları incelendiğinde bu ortaya çıkar. Şöyle ki konuyla hiç alakalı olmayan isimler oturak ortamına uygun mısralar eklenmiş türkü metinleri büyük ölçüde değişime uğramıştır. Bu durum Koya türkülerinin her ne kadar metin yönünden aleyhine olsa da, Konya Türkülerinin geleceğe aktarılmasında oturakların büyük rolü olduğu asla unutulmamalıdır. Konya türküleri oturaklarda yaşadığı nisbette geleceğe intikal etmiştir. Oturaklarda yaşayamayan türküler maalesef kaybolmuştur." (Sakman 2001: 51-52)

İnsanın iç dünyasının dişa vurum formatı olan türküler, eleştiri kavramının etrafından da şekillenmiştir. Bu makalede öne çıkarılmak istenilen, daha doğrusu amaçlanan, eleştiri kavramıyla Konya türkülerinin bağdaşıklığının ortaya konulması olacaktır. Burada yer alan türkü örnekleri Konya türkülerini içeren eserlerden (Küçükbezirci 2006; Odabaşı 1999; Sakman 1999; Halıcı 1985) seçilmiştir. Aşağıda türkü örnekleriyle konu farklı yönleriyle ele alınacaktır.

\section{KONYA TÜRKÜLERINNDE ELEŞTİRİ KÜLTÜRÜ}

\section{Evlilikle İlgili Eleştiriler}

Konya türkülerinde eleştiri kavramının en fazla görüldügü nokta, geçiş dönemleri içerisinde ele alınan evlilik müessesesi olmuştur. Burada daha çok karşıllksız kalan aşklar, zoraki evlilikler, ebeveynin evlenecek çocuklarına müdahil olması, evlenilecek gencin işi ve gelin gidilen evin işlerinin zorluğu ön plana çıkan hususlar olmuştur. Aslında türkülerde görülen hususlar doğal hayatın içerisinde karşılaştığımız noktalardır. Konuyu örnekler etrafında ele alacak olursak; 


\section{a. İstenmeyen kişiyle evliliğin eleştirisi}

İnsan hayatının en önemli aşamalarından biri olan evliliğin gönüllere uygun olmaması bu türkünün oluşumunun ana sebebidir. Burada çıkış noktası bulamayan gelin anacak dersini sözlerle anlatmıştır.

Aşağıdaki örneğimiz Çocuk Türküsü adı taşır ve "Bir genç kız, on bir on iki yaşlarında bir çocukla evlendirilir. Genç kız zorla evlendirildiği çocuğun davranışlarını türküleştirir." (Küçükbezirci 2006: 31).

Zabah olur çocuk gider oyuna

Oynar oynar taş doldurur goynuna

Gelen geçen şamar vurur boynuna

Ben güzelim, bir çocuğa virdiler

Virdiler de günahıma girdiler

Naha çocuk gebereydin, öleydin

İlân olup deliklere gireydin

Zabah olur, çarığını giyemez

Çifte gider bir dönüm yir süremez

Eve gelir halin nedir diyemez

XXX

Elime virdiler misır darısı

Yanıma kodular kadi yavrısı

Bağa diller şu çocuğun garısı (Küçükbezirci 2006: 31-32)

Bir başka örnek ise Durmam Türküsü'dür. Konya'da nişanlı olan ve nikah hazırlığ 1 yapan bir kıza âşık olan kral bir taksi ile kızı Atina'ya kaçırır. Orada üç çocuğu olur. Demir çarık ve demir asa ile nişanlısını arayan delikanlı bir gün Atina'da kızın yardımıyla saraya girer, nişanlısı olduğunu anlar ve kızla kaçarlar. Kralın emriyle gemide üç çocuklu kadının arandığını duyunca kız çocuklarından ikisini denize atar, yakalanmadan gelirler ve kız babasının evinin kapısını çalarken bu türküyü söyler:

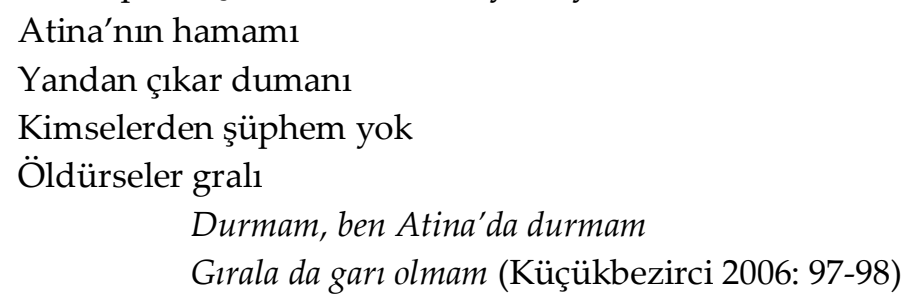

\section{b. İstenilmeyen yere verilince anne ve babaya yapılan eleştiri}

Görücü usulu evliliklerde daha çok görülen ve çocuklar üzerinde anne ve babanın söz hakkının etkili olduğu, çocukların fikirlerinin çok da önemsenmediği durumlar da türkülerde eleştirilen hususlardan olmuştur. Aşağıdaki İkindinden Yakın adlı türküde genç kız gelin olduğu pişmanlığını türkü ile dile getirmektedir. Bu pişmanlığın gerisinde anne ve babaya duyulan öfke de türküye yansımıştır.

İkindinden yakın benim fenarım

Köşelerde fırıl fırıl dönerim

Boşa gitti emeklerim yanarım 
Hani benim allı pullu yışmağım

Anne gelin olduğuma peşmanım

Annem babam başta benim düşmanım (Küçükbezirci 2006: 84)

\section{c. Kızın gelin olurken ailesine eleştirisi}

Evliliği düşünmeyen genç kızın, evlendirilmesini âdeta aileden kendisinin gönderilmesi gibi algılaması sonucu bir öfkeyle aşağıdaki türküde dile getirmiştir. Kız Gelin $A \breve{g} \imath d \imath$ adını taşıyan türkü genç kızın ailesine sitem yüklüdür:

Mahallede büyük müydü gapımız

İçiğizde ben miydim kötünüz

Ben gidiyim sakin olun hepiniz

Gel, gizin evleri gal

Şen oğlan evleri şen

Daminizda ot muydum

Üstünüzde yük müydüm

Bir gız size çok muydum

$X$

Baba bosdanın bitti mi

Bitdi de gola yattı mı

Aşın ekmeğin yitdi mi (Küçükbezirci 2006: 112)

\section{ç. Çobanlık mesleğini yapanla evliliğin eleştirisi}

Evlenecek genç kızların hayallerindeki delikanlının işiyle ilgili çeşitli isteklerin ya da beklentilerinin olması doğaldır. Bazen öyle durumlar olmuştur ki hayallerinde bekledikleri işi yapmayan bir gençle evlenmek zorunda kalan genç kızlar bu durumu türküleştirmişlerdir. Örneğin Çoban Türküsü adlı türkü de çobanlık mesleği çeşitli yönleriyle eleştirilirken kızların çoban ile evlenmemesi istenmektedir.

Çobanın yatağı küllük eteği

Ağır misafiri çoban köpeği

Varman gizlar varman bitli çobana

Ardı sürek sürek itli çobana

Çobanın yidiği helva topağ

Ağır misafiri koyun köpeği

$X$

Çobanı dağdan inme mi sandın

Gutnuyu gumaşı giyme mi sandın

Emmisinin gızını alma mı sandın (Küçükbezirci 2006: 33)

\section{d. Zor işle karşılaşan gelinin eleştirisi}

Bazen öyle olmuştur ki genç kız gelin olarak gittiği ailede gördüğü çalışma ortamını beğenmemiş, hatta işlerin zorluğuna dayanamamıştır. Aşağıdaki Burçak Tarla Türküsü adlı türkü de bu durum ele alınmaktadır:

Yarım yumurtadan tirit ideller

Burçak tarlasına gelin ideller

Aman ne zormuş burçak tarlası

Burçak tarlasına gelin olması 
Elimin gınasını çamur itdiler

Gözümün sürmesini kömür itdiler

Burçak tarlasına gelin itdiler (Küçükbezirci 2006: 113)

\title{
e. Sevip de alamayınca yapılan eleştiri
}

Sevdaları konu alan türküler içerisinde yarım kalan sevgiler de ele alınmıştır. Burada sevgili ile kavuşmanın önüne çıkan engeller türkülerde bazen sitemkâr bir hava ile ele alınmıştır. Aşağıdaki Hani Benim Sırma Saçlı Sevgilim (Konyalı) adlı türküde de bu durum konu edinilmiştir:

Hani benim sırma saçlı sevgilim

Aldı da gitti aklım fikrim yüreğim

Konyalım yürü yürü Konyalım yürü

Aldattılar bizi vermediler kızı

Yanağında duruyor izi (Odabaşı 1999: 63)

\section{f. Yâr üstüne ikinci evliliğin eleştirisi}

Yine türkülerde olumsuz bir durum olarak görülen ve eleştiri kavramı içerisine dahil edebileceğimiz bir diğer durum ise sevgiliye yapıla ihanettir. Aşağıdaki Kale Türküsünün (2. bent) bir bendinden sevgili üzerine evliliğe duyulan kızgınlık ve kırgınlık vardır:

Galeden indim yan yana

Yanlarim dolu bayan

Yâr üsdüme evlenmiş

Dayan yüreğim dayan (Küçükbezirci 2006: 54)

Evlerinin Önü Ak Dut Ăgacı adlı türküde de yârin ikinci evliliği eleştirilmektedir:

Evlerinin önü (ey aman ey aman ey aman dalgalı aman) ak dut ağacı (yavrum akdut ăgacı gel) kalır ağacı gel)

Dökülür yaprağı (ey aman ey aman ey aman dalgalı aman) kalır ağacı (yavrum

Ben bu dertten öldüm (ey aman ey aman ey aman dalgalı aman) nedir ilâcı (yavrum nedir ilâcı gel)

\author{
Yâr üstüme evlendi \\ Yavrum adın dillendi (gel) (Sakman 1999: 80)
}

\section{Sevgiliye Eleştiri}

Türkülerin içerisinde en sık işlenen konuların başında sevda gelir. Burada sevgiliye duyulan aşk, sevgilinin güzelliği, vasıfları vb. pek çok konu işlenirken bazen sevgilinin eleştirildiği de görülür. Örneğin, Tosun At Yorulur Gönül Yorulmaz türküsünde sevgilinin davranışlarının, seven kişinin hal ve davranışlarını olumsuz etkilemesi eleştirel olarak ele alınır:

Tosun atın iyisine binilir

Çayır çimenlik yerde inilir

Kara gözlüm ne bakarsın kapıdan

Sensin beni doğru yoldan sapıtan (Odabaşı 1999: 39)

Yine bu bağlamda düşünülebilecek Meram Bă̆ları Da Benim Durağım adlı türküde de sevgilinin davranışları eleştirilmektedir:

SEFAD, 2017 (38): 419-432 
İler yarini alır gider bahçeye

Ben derdimi çıkıladım bohçaya

Şimdi rağbet güzel iken [?] akçaya

Söğüdün yaprağı narindir narin

İçerim yanıyor dişarım serin

Halimi sormuyor muhannet yarim (Odabaş1 1999: 57)

Eremedim Vefâsına Dünyanın (Aksaray Develisi) adlı türküde de hem istenilenin elde edilemeyişi konu edilirken, türkünün deavamında seviliye yapılan bir eleştiri söz konusudur:

Eremedim vefâsına dünyanın (Leylâm Leylâm dünyanın)

Bülbül gonmuş sarayına Gonya'nın (Leylim leylim yar Gonya'nın)

Aksaray'dan Bakırtolu'na yol gider (Leylâm Leylâm yol gider)

Sürmelenmiş elâ gözlü yâr gider (leylim leylim yar yar gider)

Uzamışsın hay sevdiğim dal gibi (Leylâm Leylâm dal gibi)

Gelip geçen selâm vermen el gibi (leylim leylim yar el gibi) (Sakman 1999: 76)

Yörüdü Yâr Yörüdü (Caminin Müezzini) adlı türkünün aşağıdaki ilk iki bendinde de genç kızın ağzından sevgiliye yapılan eleştiri vadır:

Yörüdü yâr yörüdü

Dağı duman bürüdü

Alacaksan al beni (hocam aman)

Fidan ömrüm çürüdü

Elinde gümüş şamdan

Kaldır perdeyi camdan

Alacaksan al beni (oğlum aman)

Ben usandım bu candan (Sakman 1999: 177)

\section{Kaynananın Eleştirisi}

Gelin kaynana çatışması sözlü gelenek içerisinde farklı türlerde çeşitli cepheleriyle işlenmiştir. Bu durum bazen kaynanının dilinden gelinin eleştirisi olarak, bazenden de gelinin dilinden kaynananın eleştirisi olarak karşımıza çıkar. Aşağıdaki türkü örneklerinde kaynanaya yapılan eleştiri vardır:

Örnek 1:

Gaynanam kümese varsa

Bülbüller gözünü oysa

Top yumurta bana varsa

Ben yisem de oğlu baksa

Gaynanam hamama varsa

İki ayağı birden gaysa

Parlak babıcı bana galsa

Ben giysem de oğlu baksa (Küçükbezirci 2006: 47) 
Örnek 2:

Edik edik gaynana

Ön dişi gedik gaynana

Oğlun lokum getirmiş

Sensiz yidik gaynana

Patla da çatla gaynana

Irafta et var gaynana

Zilifinde bit var gaynana

Oğlun neler getirmiş

Sensiz yidik gaynana

\section{4. Ölüm ve Öldürmeyle İlgili Eleştiriler}

Türküler içerisinde konu olarak ağıt edası taşıyan metinler de vardır. Bu metinlerde daha çok ölüm olayı, ölen kişiye duyulan sevgi ve onun hatırasını yaşatma ve ölüm sebebinin değerlendirildiği görülür. Bu noktada aşağıdaki Mezar Arasında Harman Olur Mu (Kazımım) adlı türküde ölen Kazım'ın ardından onu öldüren kişiye duyulan öfke vardır:

Mezar arkasinda harman mi olur

Kama yarasina annem derman mi olur

Aman kamayı sokan insan mı olur

Amanın Kazım'ım yandım elinden

Aman aman Kâzım'ım ben yanıyorum ben ölüyorum (Odabaşı 1999: 41)

Yine aşağıdaki türkü örneğinde de ölüme sebebiyet veren nalbanta karşı duyulan öfke misralara yansımıştır:

Yaylı geldi kapımıza dayandı

Allı gelin odasindan uyandı

Necib'in annesi nasıl dayand 1

Kafir nalbant nice kıydın canıma

Bu katillik kalmaz senin yanına (Odabaşı 1999: 35)

\section{Hastalığın Eleştirisi}

Aşağıdaki örnek metnimizde de hastalık neticesinde ölüm olayının ardından yakılan bir ağıtta, ölüme sebebiyet veren hastalığa karşı gösterilen sitem konu edinilmiştir:

Anne beni galdır gezdir

Tabudum düzdür, mezarım gazdır

Vadem yakın ömrüm azdır

Ne yaman derdim var benim

Öğ̈̈̈lmedik yarelerim var benim (Küçükbezirci 2006: 59)

Hastalıklara karşı gösterilen hassasiyetlere bir başka örnek ise Hastane Türküsünden seçilen aşağıdaki metindir. Burada da görüleceği üzere hastalıkla ilgisi olan hastane, doktor birlikte ele alınmıştır:

Hastanenin bacaları

Ne uzundur geceler

Gur'an okur hocaları

Dokdur beğim insaf eyle (Küçükbezirci 2006: 71)

SEFAD, 2017 (38): 419-432 


\section{6. İftiranın Eleștirisi}

İnsan hayatında en istenilmeyen durumların başında, kişinin işlemediği bir fiille ya da işlediği bir fiilin yanlış anlaşılması sonucu olumsuz değerlendirmeye tabi tutulmasıdır. Kısaca iftira kavramı bağlamında değerlendirilebilecek bu hassas durum türkülerin dilinde de varlık göstermiştir. Elbette burada yanlış değerlendirilen konu eleştirel bağlamda ele alınmıştır. Örneğin, aşağıdaki Harman Yeri Türküsünde Konya'nın Araplar semtinden geçiş sırasında oluşan iftira konusu ele alınmaktadır:

Harmanıma uğradım

Ayranına bostan doğradım

Araplar'dan geçerken

İfdiraya uğradım

$$
\begin{aligned}
& \text { Hopla mavilim hopla } \\
& \text { Al beni goynuna sakla } \\
& \text { Altın ister ak gerdan (Küçükbezirci 2006: 61) }
\end{aligned}
$$

\section{Komşulara Eleştiri}

Türkülerde eleştirel bakış açısı çok farklı kesimlere yönelebilmiştir. Örneğin aşağıdaki Celal Türküsünde ölüm karşısında komşuların üzüntüyü paylaşmaması, yani komşuluk gereklerini yapmaması eleştirilmektedir:

Yüce dağ başında ıldız ışılar

Celal'ı vurmuşlar ganı fışılar

Duydu da gelmeyyor, zalim gomşular

Glyma celal giyma, nar danesiyim

Annemin babamın bir danesiyim (Küçükbezirci 2006: 79)

\section{Yaşanılan Hayata/Feleğe Eleştiri}

Türkülerde sık işlenen konuların başında, kişinin hayattan beklentilerini bulaması durumunda hayata karşı duyduğu öfke ve serzeniş gelir. Bu durum bazen başına gelenin kabullenilmemesi neticesiyle eleştirel bir biçimde mısralara dökülür. Aşağıdaki Söyletme Beni Derdim Büyüktür türküsünden alınan örnek parçada da görüleceği üzere hayatta karşı âdeta bir küsme durumu söz konusudur:

Söyletme beni derdim büyüktür

Ümüdim gönlüm çoktan sönüktür

Hayatım bana bir koca yüktür

Gönül bağında baykuşlar öter

Bu acı bana ölümden beter (Odabaşı 1999: 59)

Yine Sille Türküsünde de yaşanılan hayatta karşılaşılan durumla çile kavramı etrafında ele alınmıştır.

Şu Sille'nin minaresi daştan

Çok doldurma ben içmem tasdan

$$
\begin{aligned}
& \text { Aman Sille, Sille, Sille } \\
& \text { Çektiğim çille, çille, çille }
\end{aligned}
$$

Şu Sille'nin minaresi mercandan

Yavrum ben içemem filcandan (Küçükbezirci 2006: 95) 
Aşağıdaki Barakanın Alt Yanında Bahçeler adlı türkün seçilen bölümde de başa gelenin kabullenilmeyişinin bir serzenişi vardır:

Hastalandım hastaneye yatırın

Sağıma soluma yastık getirin

Ben ölüyom ben[i] anama götürün

Ah anam yazım kaderim böyledir

Aşk adamı deli deli söyletir (Sakman 1999: 49)

Beni Şad Etmedi Şu Çark-ı Felek adlı türkünün ilk bölümünde de görüleceği üzere feleğe bir sesleniş vardır:

Beni şad etmedi şu çark-1 felek (2)

Ağlarım ben âh ü feryâd iderek (2) (Ah)

Sevmezler dertliyi mecnûn diyerek (vay) (2) (Sakman 1999: 51)

\section{Hapishanede Dıșanıdaki Yakınların Eleștirisi}

Bir insan için en istenilmeyecek durum özgürlügünden yoksun olmaktır. Elbette ceza ve infaz kurumlarının varlığı toplumdaki huzuru sağlamak için verilen cezaların gerçekleştirildiği mekanlardır. Ancak bazen öyle durumlar olur ki, insan istemeden de olsa cezaevi hayatıyla karşılaşabilmektedir. Toplum hayatından ve sevdiklerinden uzak bir hayat sürmek zorunda kalan kişinin, geride bıraktıklarından hatırlanma ve unutulmama beklentisi içine girmesi gayet doğaldır. $\mathrm{Bu}$ durumun aksi geçekleşmesi durumunda kişinin psikolojisini en güzel anlatan unsurlardan biri şüphesiz türküler olmuştur. Elbette bu türkülerde de sitem ve eleştiri geniş yer tutmuştur. Örneğin, AKSINNE I adlı türküde de hapishanedeki kişinin dışarıyla iletişimini sağlayan mektubun gelmemesi, dışarıdaki hayatın değişikliklerinin fark edilememesi beraberinde sitem ve eleştiriyi getirmiştir:

Bilmem hayal midir anam anam

Bilmem düş müdür gel gel aman

Mektubun gelmiyor anam anam

Yollar gış mıdır gel yürü yollar gış mıdır

Gine yeşillendi anam anam

Meram bağları gel gel anam

Bize mesken oldu anam anam

Mapus damları (Halıc1, 1985)

\section{Savaşta Düşmana Eleştiri}

Savaşları konu edinen türküler içerisinde düşmana karşı yapılan eleştirel değerlendirmeler yer bulabilmektedir. Seferberlik Türküsünde de İngiliz askerlerine karşı yapılan bir eleştiri söz konusudur:

İngiliz askeri saman gafalı

İstikam içinde körü topalı

Binbaşı kakmış eli sopalı

Önüne gatmış körü, topalı

Arşın arşın üleşmeye gideriz

Akdeniz'i dolaşmaya gideriz

Anneleri ă̆latmaya gideriz (Küçükbezirci 2006: 34) 


\section{SONUÇ}

Sözlü kültürde önemli bir yeri olan türküler, insan hayatını bütünüyle kuşatmıştır. İnsanı ilgilendiren her konu, insanın baktığı olumlu ve olumsuz pencereden türkülere yansımıştır. Burada Konya özelinde türkülerde dile getirilen olumsuz durumlar ele alınmıştır. Elbette bu olumsuz durumlara karşı gösterilen eleştirel bakış açısının altında, o durumun varlı̆̆ndan öte, düzelmesi/düzeltilmesi ve beklentilerin olumlu anlamda karşılaması ya da bir iç döküş yatmaktadır.

Tabi, konu çok farklı değerlendirilebilir. Türkülerde var olan eleştiri ve siteme ait konunun, olumlu sonuçlanmadığı durumlarda da bir iç döküş, dinleyenlerle kurulan bir duygudaşlık ön plana çıkmaktadır. Dinleyen kişinin türküde işlenen konuda kendini bulabilmesi de beklenen durumlar arasında sayılabilir.

Bazen türküyü yakan, türküde işlenilen konuyu kendi yaşamamış; ama etrafında gördüğü bir olaydan etkilenmiş de olabilir. Burada da aslında insani yön öne çıkmakta; acı, kızgınlık, sitem ve beraberinde eleştiri mısralara başkaları tarafından dökülmektedir.

Yine hastalık ve ölüm konusunun ele alındığı metinlerde bir çaresizlik söz konusudur ve burada olumsuz durumu önleyememenin verdiği acının da eleştiri zeminini oluşturduğu görülmektedir.

Kişiler arasındaki sürtüşme durumunda; gelin kaynana, düşmana karşı duyulan öfke de olduğu gibi gösterilen tepkinin bir formatı olarak türküler kullanılmıştır. Yine, sevgili ile kavuşamama, sevgilinin başka biriyle evlendirilmesi, sevgiliden beklenen davranışların tam olarak görülememesi durumlarında ataerkil yapının ve toplumsal örfî düzenin önemi büyüktür. Aslında bu gibi durumların altında da genelde töreye karşı yapılan bir eleştiri vardir.

Ama hepsinden önemlisi türkülerde işlenilen olaylarda görülen eleştirel bakış açısının mısralara dökülmesi; hem konunun dinleyicilerle paylaşılmasını beraberinde getirmiş, hem de türkünün yaşama süresiyle anlatılmak istenen durumun geleceğe taşınmasını sağlamıştır. 


\section{SUMMARY}

Folk songs are the main important types of folk poetry. Folk songs, are contained within richness of Turkish oral culture for centuries, have reflected our people's love, liking, happiness, sadness etc. Both folk songs indicate variety with idiocratial melodies and show distinctness in terms of theme and form. Also, folk songs can be both anonymous and personal. In folk songs, all circumstances that human can experience in the daily life, have been treated as theme. Of course, there are critical approaches thatit is in viewpoints about daily life, in folk songs. In folk songs, Konya's folk songs have idiocratial and different position. In this paper, culture of criticism have been analyzed in Konya's folk songs broadly and function of folk songs have been tried to revealed on causes, types, verges etc. of folk songs. In this point, specific to Konya's folk songs, main subjects that include critical point of view have been revealed with examples. Specially, it has been seen that critics have increased about several aspect of marriage; also, personsaround human have been cricitised darling, motherinlaw, neighbour, intimates, enemy etc. as it can be seen in examples. In addition, illness, death, unexpected situations have been cricitised in folk songs.

Under the critical view against negative cases of folk songs, there is an expectation of fixing that negative cases or to meet the expectations or an internal collapsing. Of course, this topic can be evaluated in different ways. When criticism and reproaches in the folk songs don't end in positive sense, an internal collapsing and sympathy with the listeners come into prominence. It's expected that listeners can find themselves in the case of the folk songs. It's the most important of all, criticism written in verses makes it possible not only to share the case with the listeners but also to carry the case told by life time of the folk songs to the future. 


\section{KAYNAKÇA}

DIZZDAROĞLU, Hikmet (1969). Halk Şiirinde Türler. Ankara: Ankara Üniversitesi Basımevi.

EKICI, Metin (2007). Halk Bilgisi (Folklor)/Derleme ve Inceleme Yöntemleri. Ankara: Geleneksel Yay.

HALICI, Mehdi (1985). Konya Sazı ve Türküleri. İstanbul: Özden Matbaacılık.

KÜÇÜKBEZİRCI, Seyit (2006). Konya Merkez Türküleri. Konya: İl Kültür ve Turizm Müdürlüğü Yay.

ODABAŞI, A. Sefa (1999). Dünden Bugüne Konya Türküleri. (haz. Ali Osman Öztürk). Konya: İl Kültür Müdürlüğü Yay.

SAKMAN, Mehmet Tahir (1999). Konyalı Mazhar Sakman'dan Türküler. Konya: Konya Valiliği İl Kültür Müdürlüğü Yay.

SAKMAN, Mehmet Tahir (2001). Dünden Bugüne Konya Oturakları. Konya: Milenyum Yay. www.tdk.gov.tr

YAKICI, Ali (2007). Halk Şiirinde Türkü/Tanım-Tasnif-Inceleme-Metin. Ankara: Akçă̆ Yay.

YAKICI, Ali (2010). "Somut Olmayan Kültürel Mirasın Somut Mekânı: Konya Barana Odaları". Millî Folklor 22 (87): 94-100.

YARDIMCI, Mehmet (2008). Başlangıcından günümüze Türk Halk Şiiri/Anonim Halk Şiiri, Âşık Şiiri, Tekke Şiiri. Ankara: Ürün Yay. 